\title{
A comparative analysis of the structure of the dentinoenamel junction in mammals
}

\author{
Carlos A Oliveira ${ }^{\S}$, Lilian P. Bergqvist ${ }^{\dagger}$ and Sergio R. P. Line ${ }^{\S}$

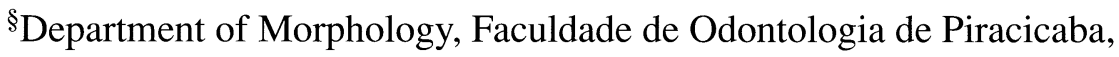 \\ Universidade Estadual de Campinas, Piracicaba-SP, Brazil \\ ${ }^{\dagger}$ Department of Geology, Universidade Federal do Rio de Janeiro, Ilha do Fundao, \\ Rio de Janeiro-RJ, Brazil
}

(Received 3 July and accepted 7 December 2001)

\begin{abstract}
Studies of the gross morphology and microstructure of teeth have provided a great deal of information about the function and evolution of mammals. Among the structural features studied, the dentinoenamel junction has received relatively little attention. In the present work, we used ground sections to perform a comparative analysis of the structure of the dentinoenamel junction (DEJ) among diverse mammalian species. Among the species studied, only two (human and Miguelsoria parayirunhor) presented a scalloped DEJ. In the other 14 species analyzed, the DEJ surface was formed by tiny spikes and depressions, corresponding to the impression of enamel prisms. Our results show that the topography of the DEJ in the analyzed taxa apparently does not relate to dietary, functional or structural features. (J. Oral Sci. 43, 277-281, 2001)
\end{abstract}

Key words: tooth; dentinoenamel junction; mammal; evolution.

\section{Introduction}

Studies of the gross morphology and microstructure of teeth have provided a great deal of information about the function and evolution of mammals (1-4). The changes of tooth form during mammalian evolution provide evidence

Correspondence to Dr. Sergio R. P. Line. Department of Morphology, Faculdade de Odontologia de Piracicaba, Universidade Estadual de Campinas, Av. Limeira 901, 13414-018 Piracicaba-SP, Brazil

Tel: +55-19-3412-5333

Fax: +55-19-3412-5218

E-mail address: serglin@fop.unicamp.br. of a shift from molars capable of puncturing and shearing to those capable of crushing and grinding. The development of new cusps was a key step that allowed mammals to diversify their diets (5). The increase in the complexity of tooth form was also accompanied by changes in enamel structure. The development of Hunter-Schreger bands (HSB) improved the physical properties of enamel. These bands can strengthen enamel with respect to tensional forces, preventing the propagation of vertical cracks (6). These features were key steps that permitted new types of diet, allowing the diversification of mammalian species. Accordingly, there was a strict correlation between masticatory function and the changes in tooth form and structure during mammalian evolution.

Enamel is supported by dentin. These tissues adhere firmly at the dentinoenamel junction (DEJ). The dentinoenamel junction is well observed in ground sections, where it appears as scalloped edges. Scanning electron microscopy analysis has shown that the scalloped pattern is formed by a three-dimensional complex of ridges (7). Analysis of DEJ microstructure has usually been limited to human teeth, whereas the DEJ of other mammalian species has rarely been studied (8). The presence of ridges is believed to increase the adhesion between dentin and enamel, helping to prevent shearing of the enamel during mastication. The development of more conspicuous ridges in the incisal and occlusal areas, which are subjected to strong bite impact, gives further support to this hypothesis. The purpose of the present work was to compare the form of the dentinoenamel junction among diverse mammalian species, and to show how this structure relates to dietary and structural features, such as masticatory habits and enamel microstructure. 


\section{Materials and Methods}

Animals: The dentinoenamel junction was studied in posterior teeth of diverse extant mammalian taxa and two extinct mammalian species from the Palaeocene (Miguelsoria parayirunhor, Tetragonostypops apthomasi, Table 1). At least two teeth were examined for each species, with the exception of the two extinct animals, for which only one tooth was studied. Three sections were made for each tooth analyzed. We also included human deciduous teeth and teeth of a person with hypocalcified amelogenesis imperfecta. The body mass and feeding habits of the animals were obtained from Nowak, $1991(9,10)$.

Microscopic analysis: Teeth were embedded in polymethylmethacrylate resin and sectioned longitudinally with a low-speed saw (model 650, South Bay Technology Inc., USA) fitted with a diamond-edged blade. The sections were sanded to 50-100 $\mu \mathrm{m}$ with descending grades of silicon carbide paper and then polished with a whetstone. After being extensively washed in tap water, the sections were dehydrated, mounted in Canada balsam, examined, and photographed with a Leica DMLP light microscope. The observation of HSB was performed by polarizing microscopy.

\section{Results}

The contour of the DEJ was clearly evidenced in the ground sections as an irregular line separating the dentin and the enamel. We divided the DEJ into three categories, based on the topography of the DEJ in the taxa analyzed (Fig. 1).

Type 1: Scalloped DEJ. This type of DEJ consisted of raised ridges with varying sizes and shapes and frequency and distribution. The scalloping was more conspicuous in the cuspal region where it could reach a diameter of $30 \mu \mathrm{m}$. Scalloping was progressively reduced towards the cervical region to form a type $3 \mathrm{DEJ}$ (see below) near the cementoenamel junction. Analysis of ground sections showed that scalloped enamel was present in human permanent teeth (Fig. 2A), and in the teeth with amelogenesis imperfecta (Fig. 2B).

Type 2: Ruffled DEJ. This type of DEJ was composed of small scallops, which appeared as small undulations of up to $10 \mu \mathrm{m}$. This pattern was observed in human deciduous teeth (Fig. 2C) and in the tooth of Miguelsoria parayirunhor (Fig. 2D), in which it was especially evident in the cuspal areas. As observed for the type $1 \mathrm{DEJ}$, scalloping decreased progressively towards the cervical region of the tooth crown.

Type 3: Smooth DEJ. This type of DEJ was apparently devoid of scallops, but contained tiny spikes and depressions, with a size ranging from 3 to $5 \mu \mathrm{m}$. Closer observation of these areas revealed that the depressions corresponded to the imprint of a single prismatic structure

Table 1 Relationships of types of dentinoenamel junction with body mass, diet and structure of enamel in several species of mammals

\begin{tabular}{llccllc}
\hline Taxa & Order & DEJ type & HSB & Feeding & Mass (kg) & Individuals examined \\
Human (adult) & Primate & 1 & + & omnivorous & 60 & 5 \\
Human (deciduous) & Primate & 2 & + & omnivorous & $10-30$ & 3 \\
Human amelog. imperfecta & Primate & 1 & - & omnivorous & 60 & 1 \\
Saimiri sciureus & Primate & 3 & - & omnivorous & $0,75-1,1$ & 1 \\
Callithrix pennicilata & Primate & 3 & + & insectivorous & $0,23-0,45$ & 1 \\
Callicebus personatta & Primate & 3 & + & omnivorous & $0,51-0,7$ & 1 \\
Cebus apella & Primate & 2 & + & omnivorous & $2(1,1-3,3)$ & 1 \\
Panthera leo & Carnivora & 3 & + & carnivorous & $150-250$ & 1 \\
Felix catus & Carnivora & 3 & + & carnivorous & $1(3,3-4,5)$ & 1 \\
Cerdocyon thous & Carnivora & 3 & + & carnivorous & $6-7$ & 1 \\
Didelphis marsupialis & Marsupialia & 3 & - & omnivorous & $2-5,5$ & 2 \\
Tursiops truncatus & Cetacea & 3 & - & carnivorous & $150-200$ & 2 \\
Delfinidae & Cetacea & 3 & - & carnivorous & ND & 1 \\
Miguelsoria parayirunhor & Litopterna & 2 & + & herbivorous & ND & 1 \\
Tetragonostylops apthomasi & Astrapotheria & 3 & + & herbivorous & ND & 1 \\
Bos taurus & Artiodactyla & 3 & + & herbivorous & $800-1000$ & 1 \\
Sus scrofa & Artiodactyla & 3 & + & omnivorous & $50-350$ & 2 \\
Ozotocerus bezoarticus & Artiodactyla & 3 & + & herbivorous & $25-40$ & 2 \\
\hline
\end{tabular}

Abbreviations: DEJ=Dentin-enamel junction. HSB=Hunter-Schreger bands.

ND not determined. + present. - absent. 


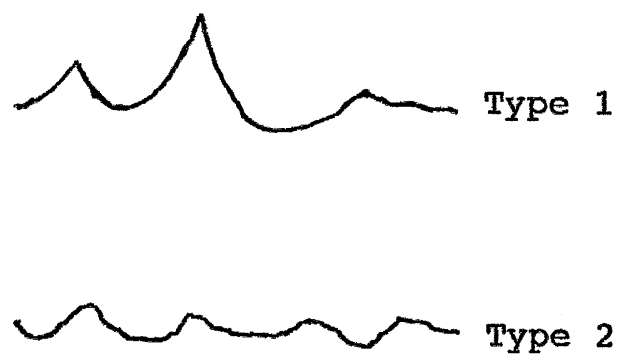

Type 3

Fig. 1 Scheme showing the three types of DEJ observed in mammals.
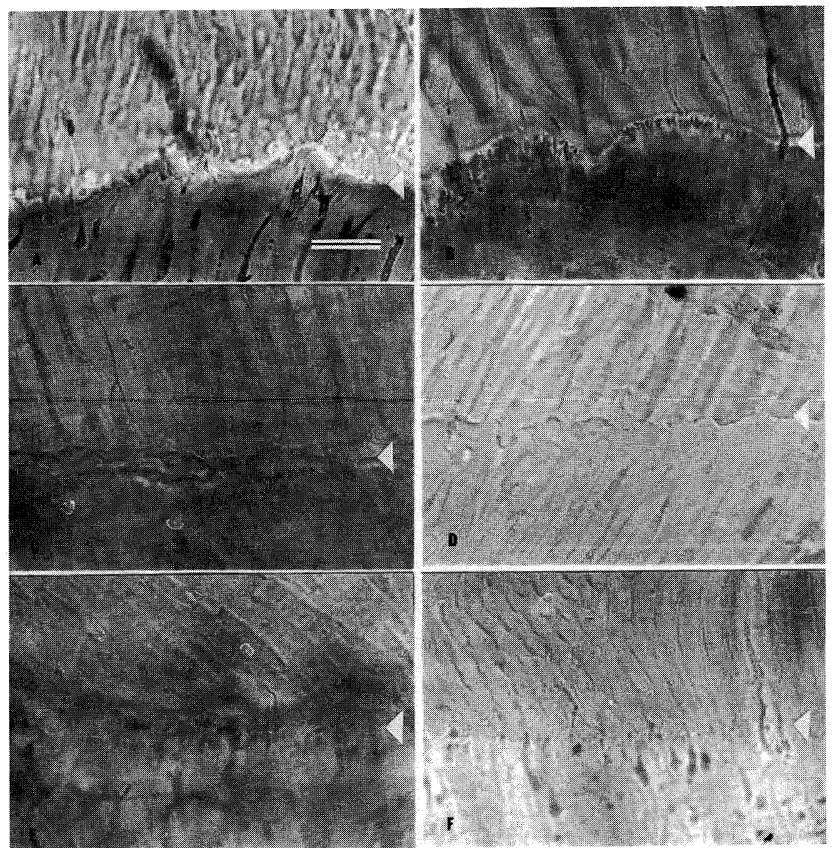

Fig. 2 DEJ of mammalian teeth. A- adult human, B- adult human with amelogenesis imperfecta, C- deciduous human, D-Miguelsoria parayirunhor, E- Ozotocerus bezoarticus, F- Felix catus. DEJ is indicated by arrowhead. All the figures have the same magnification. Scale bar $=16 \mu \mathrm{m}$.

on the dentin surface (Figs. 2E, 2F, 3, 4). This type of DEJ was observed in all the animals studied, with the exception of human and Miguelsoria parayirunhor teeth.

The results showed no apparent relationship between the microstructure of the DEJ and other functional or structural parameters, such as body mass, diet or enamel structure (Table 1).

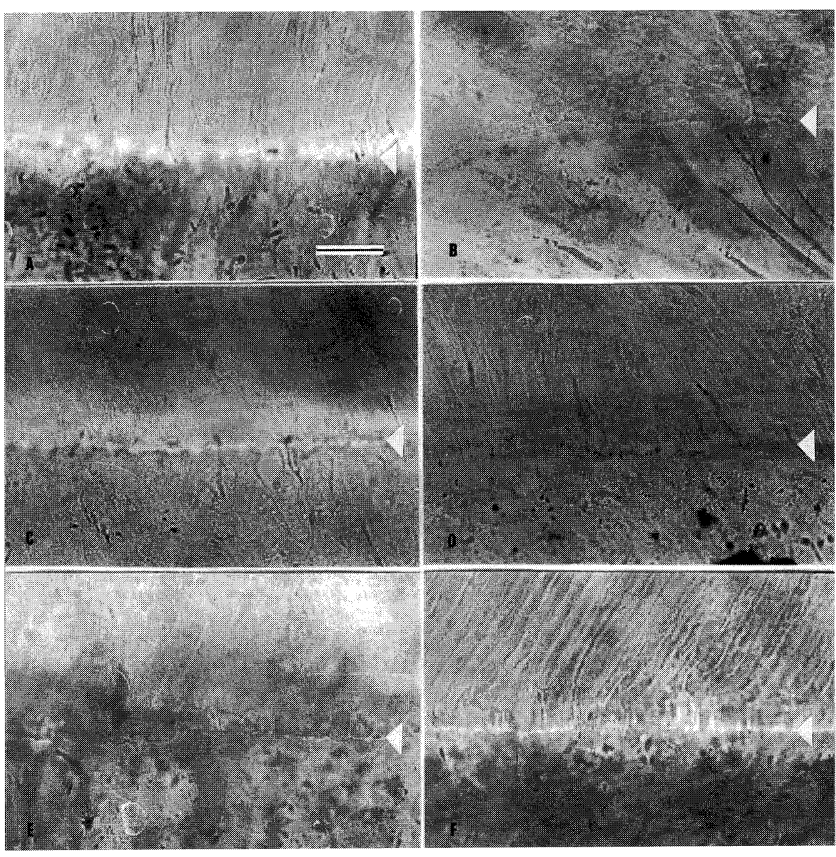

Fig. 3 DEJ of mammalian teeth. A- Saimiri sciureus, BCallibecus, C-Cebus apella, D- Callithrix pennicilato, E-Bos taurus, F- Tursiapis truncates. DEJ is indicated by arrowhead. All the figures have the same magnification. Scale bar $=16 \mu \mathrm{m}$.

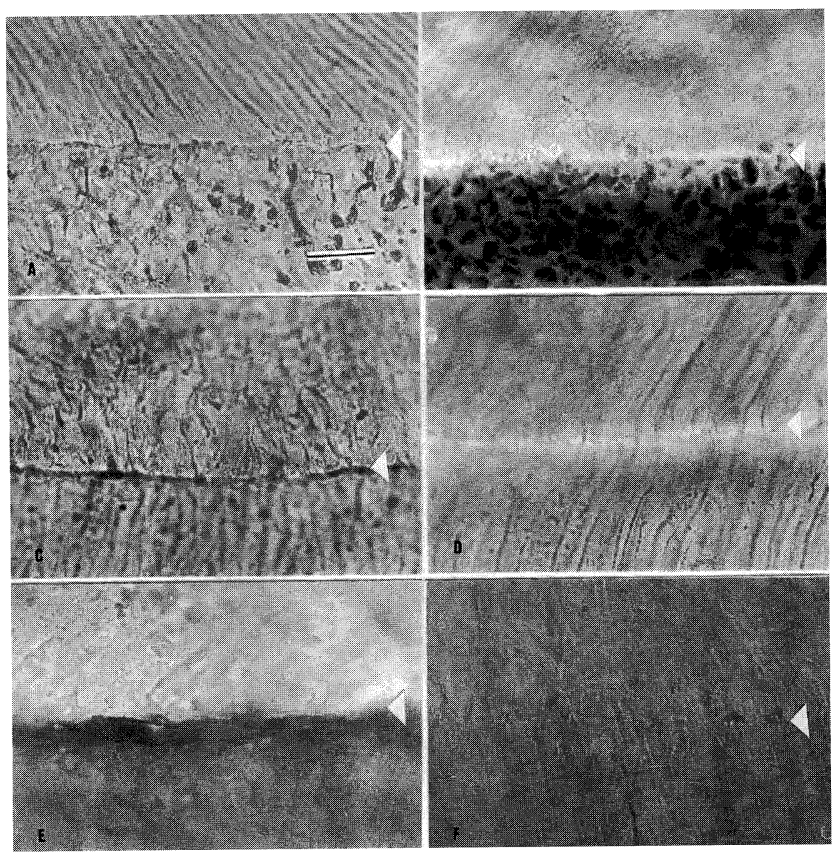

Fig. 4 DEJ of mammalian teeth. A-Sus scrofa, B-Delfinidae, C-Pantera leo, D- Didelphis marsupialis, ETetragonostylops aptomasi, F- Cerdocyon thous. $\mathrm{DEJ}$ is indicated by arrowhead. All the figures have the same magnification. Scale bar $=16 \mu \mathrm{m}$. 


\section{Discussion}

The results presented in this work have shown that the topography of the DEJ does not relate to feeding habits, since a scalloped DEJ was not present in most taxa analyzed. It is worth mentioning that our sample was composed of carnivores, herbivores and omnivorous animals. The results clearly show that the topography of the DEJ also does not relate to the masticatory forces imparted on the teeth. Chewing pressure varies directly with the cross-sectional area of masticatory muscles and inversely with the area of the chewing surface (6). The molar teeth of lions and dogs are frequently subjected to extreme tensile forces, since they are used to crush bones of prey animals (11). Likewise, the hypsodont molars of larger herbivores, such as Bos taurus, are subjected to concentrated stress near the DEJ (2). However, our results show that the DEJ of these animals is fairly smooth. Therefore, the development of ridges in the teeth of humans and Miguelsoria parayirunhor cannot be understood as a functional adaptation related to masticatory stress.

Although there is some disagreement concerning the formation of the DEJ, it is believed that the scalloped aspect observed in the DEJ of human teeth occurs because of mechanical distortions during the maturation of dentin and enamel (12). This hypothesis is supported by the absence of scallops at the future DEJ before the secretion of the enamel matrix (8). The formation of scallops may be facilitated by the orientation of collagen fibrils in mantle dentin, which are aligned at right angles to the basal lamina of the internal dental epithelium. This orientation would not effectively counteract the tensional forces on the DEJ that are thought to provoke the distortion of mantle dentin. Our results also indicate that the putative tensional forces that cause mechanical distortion of the DEJ are not related to the wavy course of ameloblasts during amelogenesis, since intense prism decussation with formation of HSB was observed in the enamel of most animals analyzed. It is also interesting to note that disturbances in enamel mineralization, which occur in amelogenesis imperfecta, did not affect the structure of the DEJ in human teeth.

The parallel evolution of a scalloped DEJ in humans and Miguelsoria parayirunhor is an interesting phenomenon. The development of the DEJ in the tooth of Miguelsoria parayirunhor has apparently occurred in the absence of any selective pressure, since this animal was a relatively small herbivore. Parallel evolution seems to be a usual feature in the evolution of teeth. The development of prisms in enamel occurred independently in several mammalian lineages as well as in the agamid lizard Uromastyx $(13,14)$. Analysis of the evolution of enamel microstructure shows that the occurrence of some specific apomorphic characters, such as the pattern of the HSB (Schmelzmuster), is frequently restricted to a systematically related group. In this regard, analysis of the DEJ in pongids and extinct hominids would provide important information on the evolutionary relationships among these species. Likewise, studies on the microstructure of the DEJ and prismatic enamel in other Litopterna would help to establish possible systematic relationships in this extinct order.

\section{Acknowledgments}

We thank Regina Lex Engel from the Municipal Zoo of Piracicaba, who provided the teeth of most of the species studied.

\section{References}

1. Frank, R.M., Sigogneau-Russell, D. and Voegel, J.C. (1984) Tooth ultrastructure of late triassic Haramiyidae. J. Dent. Res. 63, 661-664

2. von Koenigswald, W., Pfretzschner, H.U. (1991) Biomechanics in the enamel of mammalian teeth. In Constructional morphology and evolution. Schmidt-Kittler, N. and Vogel, K. eds., SpringerVerlag, Berlin, 113-125

3. Risnes, S. (1998) Growth tracks in dental enamel. J. Hum. Evol. 35, 331-350

4. Bergqvist, L.P., Abuhid, V.S. and del Giudice, G.M.L. (2000) Mamiferos. In Paleontologia. Carvalho, I.S. ed., Editora Interciencia, Rio de Janeiro, 595-623 (in Portuguese)

5. Hunter, J.P. and Jernvall, J. (1995) The hypocone as a key innovation in mammalian evolution. Proc. Natl. Acad. Sci. USA 92, 10718-10722

6. von Koenigswald, W., Rensberger, J.M. and Pfretzschner, H.U. (1987) Changes in the tooth enamel of early Paleocene mammals allowing increased diet diversity. Nature 328, 150-152

7. Ten Cate, A.R. (1998) Oral histology. Development, structure and function. 5th ed., Mosby, St. Louis, 163-164

8. Whittaker, D.K. (1978) The enamel-dentine junction of human and Macaca irus teeth: a light and electron microscopic study. J. Anat. 125, 323-335

9. Nowak, R.M. (1991) Walker's mammals of the world, 5th ed., Baltimore: The John Hopkins University Press. Vol. I, 10-514

10. Nowak, R.M. (1991) Walker's mammals of the world, 5th ed., Baltimore: The John Hopkins University Press. Vol. II, 969-1499

11. Van Valkenburgh, B. (1996) Feeding behavior in free-ranging, large African carnivores. J. 
Mammalogy 77, 240-254

12. Marsland, E.A. (1952) A histological investigation of amelogenesis in rats. II. Maturation. Br. Dent. J. 92,109-119

13. Cooper, J.S. and Poole, D.F.G. (1973) The dentition and dental tissues of the agamid lizard, Uromastyx.

\section{J. Zool. 169, 85-100}

14. von Koenigswald, W. (1997) Evolutionary trends in the differentiation on mammalian enamel structure. In Tooth enamel microstructure. von Koenigswald, W. and Sander, P.M, eds., Balkema, Rotterdam, 203235 